\title{
Double layer glass façade in the refurbishment and architectural renewal of existing buildings in Italy
}

\author{
Silvia Brunoro ${ }^{1 *}$, Andrea Rinaldi ${ }^{2}$ \\ ${ }^{1}$ University of Ferrara, Department of Architecture, Architettura $>$ Energia Research Center, Ferrara, Italy \\ ${ }^{2}$ University of Ferrara, Department of Architecture, Architettura $>$ Energia Research Center, Ferrara, Italy \\ * Corresponding author. Tel: +39 0532 293633, Fax: +39 0532 293647, E-mail: silvia.brunoro@unife.it
}

\begin{abstract}
The aim of this paper is to assess the use of an intelligent glass envelope in the refurbishment of existing buildings in Italy in order to fit their energetic performance considering Mediterranean climate inputs. With the new European and Italian regulations on energy efficiency of buildings, envelopes are not only forced to respect heat transmission limits (e.g. U value) and to improve their thermal insulation, but also to use and receive benefits from environmental input such as passive solar gains. Comparing to the North European solutions, a glass envelope seems not to be the most suitable solution for a Mediterranean climate, mainly due to the great incidence of solar gains and the risks of overheating during summer season. Examples presented in this paper indicates how double skin glass façades, that are commonly used in new constructions where the concept starts from a low environmental impact, can be also employed in the refurbishment of existing buildings, which is the main challenge for the global reduction of $\mathrm{CO}_{2}$. An overview on the main technical of intervention can indicate to architects and planners the weakness/strength points to take in consideration in the use of a double layer glass façade in a Mediterranean climate in order to reduce the overall energy balance.
\end{abstract}

Keywords: Building envelope, Sustainable technologies, Energy retrofit, Double skin glass façades.

\section{Introduction}

This paper purpose to remark the importance of the use of sustainable technologies, such as a double layer glass envelopes, in the renewal of existing buildings in order to fit their energetic performance to different climatic inputs. This solution is mainly used in public buildings (offices and productive buildings) where the potential of a new high-tech image may easily justify high costs of realization. Moreover, the use of double layer glass envelopes is heavily conditioned by the climatic factor. The main purpose of the double glass envelope is to balance the desire for daylight and outdoor view with the concerns for heat gain and loss. The air cavity can be heated by the sun to create a warm buffer zone that protects rooms in winter and can be configured to function as a thermal chimney in summer utilizing the stack effect to remove excess heat. Case studies presented in this paper indicates how double glass envelopes, that are commonly used in new constructions, can be also employed in the refurbishment of existing buildings, which is the main challenge for the global reduction of $\mathrm{CO}_{2}$. An overview on the main technical of intervention can indicate to architects and planners the potentiality for the improvement of the existing buildings, in order to reduce the overall energy balance. The energy failure in existing building stock is mainly due to the poor insulating efficiency of the façades. Making use of hi-tech envelopes, not only the energetic balance, but also the architectural value of a building can be improved. A set of rules concerning energy efficiency in buildings has been acknowledged in Italy by enacting the Decree 311/2006, that states new standards for the energetic performance including also the existing building stock, except for cultural heritage. The experiences gained till now in other Countries suggest wide chances of interventions on building stock by promoting the use of "intelligent envelopes": dynamic and active bounding surfaces automatically able to gear their performance to the changes of the environmental conditions, as they integrates a great deal of working functional devices. Following these experiences it is possible, therefore, not only to introduce basic standard improvements but even proper architectural lifting on the building 
façades, mainly considering post war building stock that is one of the most cause of energy consumption due to the poor building techniques and the heavy state of decay.

A sustainable upgrade should mainly provide active or passive energy from renewable sources in order to achieve the highest indoor comfort by restricting the use of HVAC (Heating Ventilation Air Cooling) units and artificial lights. The most efficient technical solutions that can be used to refurbish buildings are based on fundamental principles of the sustainable architecture such as: heat gaining by collecting and storing solar energy in winter, use of passive cooling and natural ventilation in summer, maximum natural day lighting, reduction of heat loss through the walls, use of systems with low environmental impact such as dry technologies.

\subsection{Methodology}

This study examines three case studies in Italy where the refurbishment of existing building envelopes was done using a double layer glass façade. The aim of this study is to assess which technical solution can improve the energy efficiency and the global quality of the building by considering some variables:

- The climatic conditions: in Italy climate is very different from Northern Europe, where the double layer glass envelopes are largely used. The main problem is the risk of overheating in spring/summer season as, in Mediterranean climate, the energy efficiency is based not only on the performance of thermal insulation such in Northern countries, but also on the necessity to reduce big solar gains and improve ventilation in summer;

- The composition of the technical solution: in the most cases of refurbishment the original inner façade is conserved and improved by insulation, so the "double layer glass" systems turns in "hybrid" system where opaque parts of parapets are present;

- The applicability of different solutions (full height façades, cell façades, natural or forced ventilation) to the existing façade by considering operations and costs/benefits.

The evaluation was done on the basis of the following steps:

- Energetic diagnosis of the building before the intervention (mainly considering energy consumptions in operational phase);

- Examination of the project/design/technical details;

- Visit in building site during the construction;

- Monitoring of the building for one year, by considering the grade of satisfaction/comfort of the occupants and energy consumption recording.

\section{Double layer glass façades: the technical solution}

A typical double glass envelope system includes a single glass layer and a double-glazing low emissive layer separated by an air space. An operable shading device is installed in the cavity to minimize the solar heat gain in summer. In addition to the energy savings, the double envelope system has other potential benefits such as: acoustic control, water penetration resistance and an enhanced office atmosphere because of the external view and the utilization of daylight. Double glass façades in the refurbishment are generally hybrid systems, formed by the existing wall and a new glass envelope. The external envelope is a glass façade: during the winter season it supports the solar gain that, by heating the air cavity, consequently improves the thermal capacity of the whole system. The use of high - performing glasses is fundamental to obtain solar reflection and to prevent overheating. If the refurbishment is oriented to the complete substitution of the existing envelope, also the internal wall is a glass façade, forming the conventional double-layer skin. In the most cases, it's more convenient to conserve the existing wall and, after the changeover of the windows, to add up insulating panels on the structure and on the parapets. 
In winter, during the warmest hours, the heating of the air cavity is the fundamental factor that reduces the thermal losses and the air permeability through the wall. During the night, the air vents are closed, preventing the entrance of cold air. In summer, through the solar shadings, good levels of internal comfort can be obtained. Throughout the day, the cavity is closed to avoid the entrance of warm air, while during the night the natural air flue cools down the walls and the rooms.

The thermal performance of double façade systems depends on many factors, such as:

- The composition and performance of the layers (glass/glass or glass/wall, kind of glass used);

- The (height) extent of the air cavity (which can be continuous or divided in floor-height cells, in this case the ventilation is related to each cell);

- The thickness of the air cavity (which can range between $20 \mathrm{~cm}$ to 90, if it encloses maintenance routes);

- The type of ventilation in the cavity (natural or forced) that is strictly related to the height of the façade and to the climatic conditions;

- The relationships between air cavity and HVAC systems (possibility to utilize warmed air from the cavity and expel internal air. This is rare occurrence in the refurbishment).

\subsection{Typologies of construction}

Double layer glass façades can be realized in three main typologies of construction:

Full height: in this case the air cavity is continuous and comprehends the whole façade surface. The external glass layer is fixed on the existent envelope in a limited number of points (generally in correspondence of concrete border beams). Air cavity thickness ranges between 40 to $90 \mathrm{~cm}$. Pipes: the external façade is fixed to the internal by means of a common frame or punctual anchorages. The cavity is sectioned in vertical or in horizontal: this means that the surface is divided in several ventilations chimney, instead of an unique air cavity area. Air cavity thickness ranges between 40 to $90 \mathrm{~cm}$. Cells: The façade is formed by the aggregation of modular cells, independent each other, one floor height and generally not more than $30 \mathrm{~cm}$ thick. Each cell has his inlet airs. Table 1 analyzes the suitability of the typologies of construction in the refurbishment of existing buildings.

Table 1. Main typologies of construction and applicability in the refurbishment

\begin{tabular}{ccc}
\hline Typology of façade & Description & Applicability \\
\hline Full Height & $\begin{array}{c}\text { Air cavity is continuous. } \\
\text { Anchorages are punctual } \\
\text { Thickness ranges from } 40 \text { to } 90\end{array}$ & high \\
Pipes & $\begin{array}{c}\text { Air cavity is vertically sectioned. } \\
\text { The thickness ranges from } 20 \text { to } \\
50 \mathrm{~cm}\end{array}$ & medium \\
Cells & $\begin{array}{l}\text { The façade is formed by the } \\
\text { aggregation of modular cells, } \\
\text { independent each other. Each } \\
\text { cell has his inlet airs. The } \\
\text { thickness is } 20 \text { - } 40 \mathrm{~cm}\end{array}$ & medium \\
& &
\end{tabular}




\subsection{Air cavity ventilation}

The cavity in double glass façades is either naturally or mechanically ventilated. In case of natural ventilation, the air in the cavity flows naturally: if properly designed, wind flowing over the façade can create pressure differences between the inlet and outlet inducing air movement. Air vents at the bottom and at the top of the façade allows the natural flowing in the cavity by the so called "chimney effect" of the warmest air that naturally rises up. In this configuration the internal layer is the layer with thermal performance (insulation on parapets, low-e glass windows) while the external layer is single glass. The temperature in the air cavity is closer to the external temperature. Internal windows can be opened or not. If internal windows can be opened, this allows the natural ventilation of the rooms, even it's necessary to carefully evaluate the right period of opening (winter day- summer night), otherwise the positive effect of the natural air could be neutralized. Natural ventilation is not without risk. It may create a door-opening problem due to pressurization. Besides, if the air path is not appropriately designed, the solar heat gain within the façade cavity will not be removed efficiently and will increase the cavity temperature. If windows can not be opened this helps in the air cavity control, but decreases the user requirements (necessity of fresh air). In the case of forced ventilation air is compressed into the cavity by mechanical devices. The mechanically assisted ventilation systems usually use an under floor or overhead ventilation system to supply or exhaust the cavity air to ensure good distribution of the fresh air. This air rises and removes heat from the cavity and continues upwards to be expelled or re-circulated. Because air is not pumped in directly from the outdoors, there is potentially less risk of condensation and pollution in the cavity. The internal façade is generally closed and single glass made while the external layer is the insulated and performing layer. The temperature in the air cavity is more similar to the air temperature in the rooms. In areas with severe weather conditions or poor air quality, the mechanically assisted ventilation system can keep conditions in the buffer zone nearly constant to reduce the influence of the outdoor air to the indoor environment. The relationship between type of ventilation and applicability in the refurbishment is synthesized in table 2 .

Table 2. Main typologies of ventilation and applicability in the refurbishment

\begin{tabular}{|c|c|c|c|}
\hline Typology of façade & Scheme & Description & Applicability \\
\hline Natural ventilation & & $\begin{array}{l}\text { The air in the cavity flows } \\
\text { naturally by chimney effect } \\
\text { Internal layer= performing glass } \\
\text { External layer= single glass }\end{array}$ & high \\
\hline Forced ventilation & & $\begin{array}{l}\text { The air in the cavity flows by } \\
\text { means of mechanical devices. air } \\
\text { is utilized by HVAC systems. } \\
\text { External layer= performing glass } \\
\text { Internal layer=single glass }\end{array}$ & low \\
\hline
\end{tabular}

\subsection{Case studies}

\subsubsection{Torno International Headquarter in Milan}

Originally built in 1950, the building had many problems mainly related to: lack of thermal and noise insulation, overheating in summer season, lack of natural light into the offices. Big consumption was registered due to the necessity of heating in winter but most of all for the big air conditioning use in summer. An average consumption date was estimated in about 250 
$\mathrm{Kwh} / \mathrm{m}^{2}$ per year. The strategy of intervention was to coat opaque parts of façade (e.g. concrete skeleton, ground floor) with a dry coat finished with gypsum panes. The south façade, made by single layer windows and thin brick wall parapets, was replaced with full height double low-e glass windows. Starting from the first floor, a full height glass facade was overlapped. The air cavity is $55 \mathrm{~cm}$ wide, air flows naturally: at the bottom the cavity is always open thanks to a metallic grid (also helpful for maintenance routes), at the top moveable glass louvers can control the air flow in the different climatic conditions (maximum ventilation in summer, minimum in winter). Solar shadings are in the air cavity: aluminum venetian blinds in front of the internal windows. Internal wall can not be opened, this helps in the control of the natural phenomenon of the chimney effect in the cavity. Main benefits with this intervention were obtained. For first, the reduction of thermal losses due to the air cavity that acts like a warm buffer zone in winter and improves solar gain: this caused the reduction of HVAC of about $35 \%$ in winter and $40 \%$ in summer. Moreover, the improvement of noise insulation (a reduction of $6 \mathrm{Db}$ was registered). The cost of the intervention is about 1100 Euro/m².
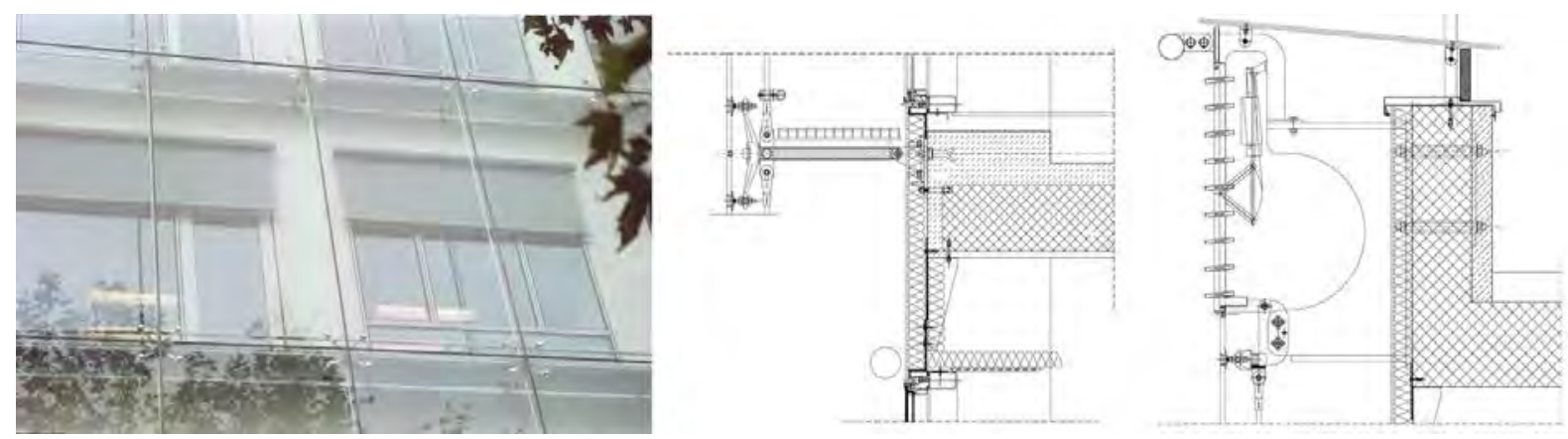

Fig. 1. Image and technical details (bottom - top) of the new façade

\subsubsection{Johnson Wax Headquarter in Milan}

The building, $20 \mathrm{~m}$ tall, was originally built in 1977 with a curtain wall façade. Main requirements that was asked to the designers were:

- to allow the natural ventilation that could be independently managed by the users of each office;

- to achieve high thresholds of natural light, even for environments located in the central part of the buildings, while avoiding the phenomena of glare and overheating of indoor air; - to ensure adequate levels of sound insulation from noise coming from the adjoining highway;

- to carry out the remediation of asbestos cladding;

- to improve the quality of architecture.

The facade of the building was replaced with a double skin façade made by aluminum windows (internal layer) and $8 \mathrm{~mm}$ safety glass layer supported by a system of spiderglass and rotules (external layer). A full height natural ventilated façade was designed to meet users and owners' s requirements. In the cavity, $90 \mathrm{~cm}$ thick, air flows naturally but mechanical fan at the top of the façade were installed to provide to forced ventilation in case of low-pressure. The façade works as a dynamic filter for the regulation of energy exchange between inside and outside. In winter time the cavity acts as a "thermal buffer" by reducing heat loss and heat gain by allowing the greenhouse effect. Internal wall can be opened: three doors per side allows natural air exchange and the access to the corridors for maintenance routes. Aluminum blinds in the cavity allows to avoid summer overheating, moreover also $90 \mathrm{~cm}$ grilled corridors contributes to shield the solar radiation. Concerning the indoor comfort, an average temperature of the rooms was calculated, ranging between $18^{\circ}$ and $20^{\circ} \mathrm{C}$ for opaque 
surfaces, and between $16^{\circ}$ and $17^{\circ} \mathrm{C}$ for glass panes. Indoor relative humidity is about 50/60\%: this means that the temperature inside of the cavity can exclude any risk of condensation. Main technical data after the refurbishment are: the reduction of thermal losses of $30 \%$, reduction of HVAC of $30 \%$ in winter and $40 \%$ in summer, noise insulation damping: $7 \mathrm{Db}$, The cost is about $1300 \mathrm{Euro} / \mathrm{m}^{2}$

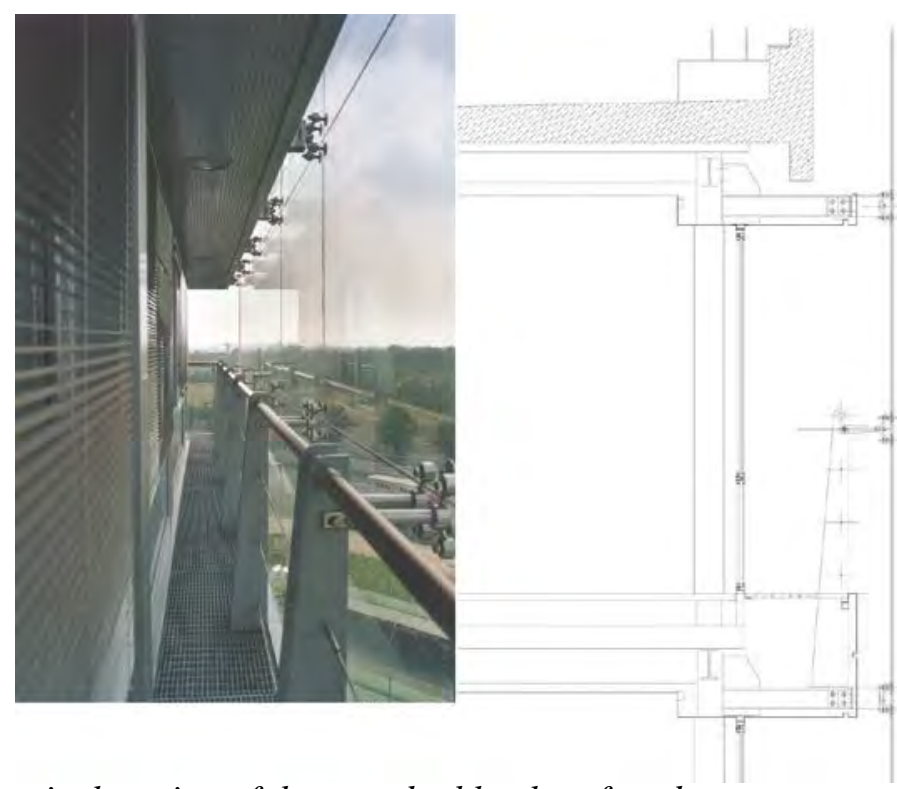

Fig. 2. Image and vertical section of the new double glass façade

\subsubsection{Hines Headquarter in Milan}

The building is a part of a commercial area, consisting of 4 buildings of the '60s. The project was organized around some architectural choices towards environmental design and energy conservation. Main design guidelines were: a new double skin glass façade on the main building, the partial covering of the internal courtyard, the creation of an indoor garden, the careful control of the natural day light. In particular, for the building towards via Bergognone, characterized by significant thermo-acoustic lacks (single-glazed windows and wooden panels as parapets without insulation) the energy retrofit was done by the removal of the existing façade that was replaced by a double skin façade on the south-west front. The air cavity is 75 $\mathrm{cm}$ thick, full height and natural ventilated. The inner envelope, made by low-e double glass, acts as thermal and acoustic insulation and solar control factor, while the external front (a system suspended by metal cables to fixed glass components), due to a special surface treatment with oxides of iron, is able to harness the positive effects of solar radiation in winter and to control the flow during the summer (solar factor $\mathrm{g}$ of $65 \%$ ). Natural ventilation is ensured by the openings at the base and the top of the façade. Moreover joints between the glass panes are open: a distance of $10 \mathrm{~cm}$, allows ventilation in the cavity during the summer to avoid overheating. For this reason, it was chosen not to govern the dynamic condition by systems of opening/closing of the inlet and outlet air vents. Main results after the refurbishment are: the reduction of reduction of HVAC of $35 \%$ in winter and $40 \%$ in summer. 


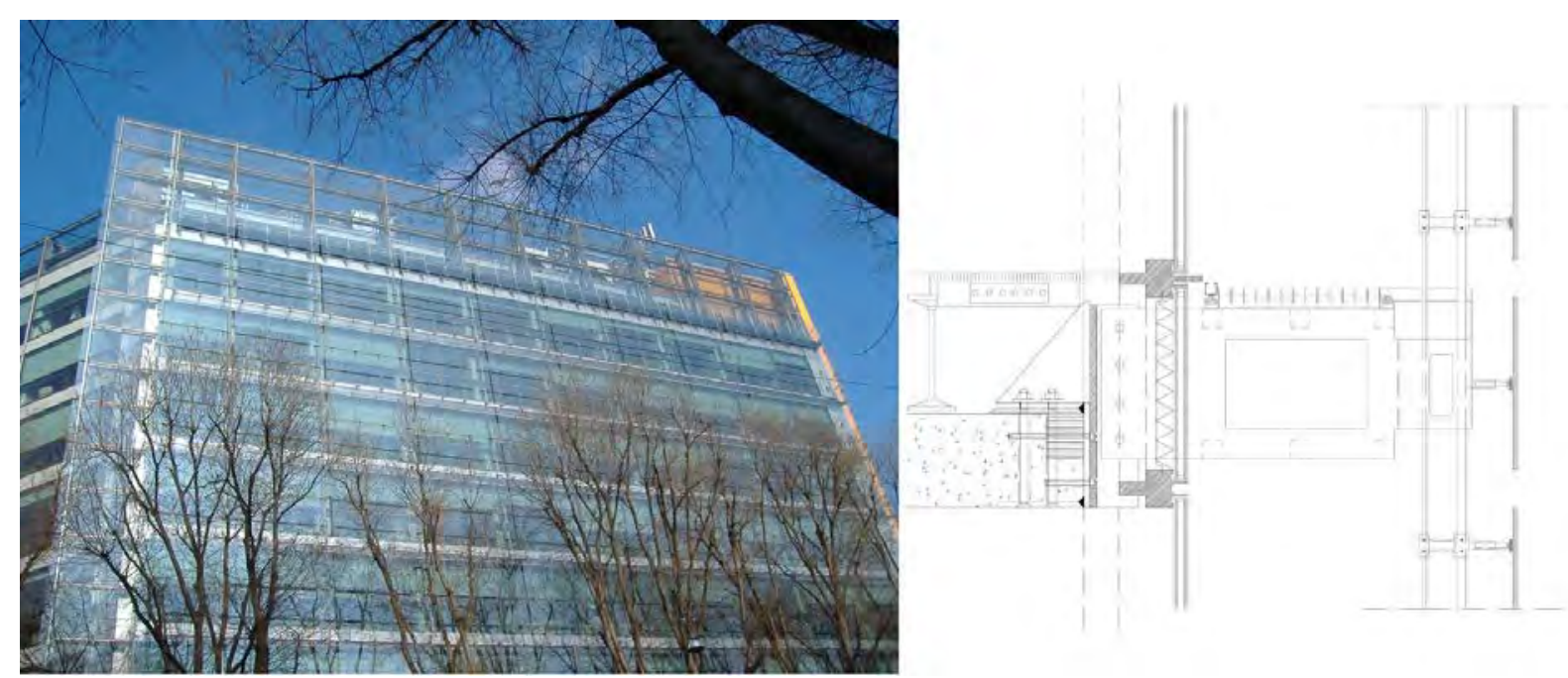

Fig. 3. Front of the building and vertical section of the new double glass façade

\subsection{Results}

By considering the case studies examined some conclusions can be made. The most useful typology in the refurbishment is the full height façade: generally the overlapping of a new glass layer doesn't greatly alter the whole system: in these cases, the original windows are replaced with double-glass windows and an insulating coating is applied on the opaque parts. The natural ventilation of the cavity doesn't involve big plant variations, this is the reason why the solution is the most suitable in case of refurbishment. The careful design of the air cavity (thickness, position and dimensions of air vents) is fundamental, so that the phenomenon of the natural draught can properly occur. The use of cells façade is the most convenient when the building is so high that the natural flow of air is impossible, even if it's not suitable for in each case. The operational route of the double skin façade in Mediterranean countries such as Italy remains unknown today. The climate conditions, warmer and wetter than in the North-European Countries, make very difficult to exploit a system of natural ventilation of the facade able to make use of its full potential performance. For this reason, the design strategies undertaken by the Italian projects have used the double-skin "buffering" system, that can reduce the heat load and meet the sound insulation and sealing requirements, rather than operate on the heat and energy recovery through installations. Because of the typical Mediterranean conditions, the natural ventilation of the rooms through the cavity was generally avoided in the most examined projects, keeping the skin closed and obtaining internal comfort through air conditioning systems. The decision to equip the inner shell with opening windows has a helpful effect on the psychological health of the people, but must be assessed in relation to the climatic conditions of the site. In the Italian context, the choice may not be appropriate since it does not provide guarantees on the benefits offered by the air present in the cavity. This choice also involves the reduction of the noise level of the system.

For the project of renovation of the Hines company in Milan, for example, the strategy of refurbishment has prioritized the issue relating to the control of the thermal load and the daylight through the use of high-performance glass rather than the use of natural ventilation in the offices. In the renovation of the Johnson Wax building, the possibility of opening the inner façade exist: this helps the comfort of users, who can enjoy natural ventilation in the workplace, even if, in the reality, the optimal conditions for opening the windows occur only during the summer night-time and the achievement of the comfort is largely delegated to the air conditioning. For the Torno International headquarters the internal façade can not be opened and an external skin made by laminated security glass was realized. The lower air vent is full open, the upper is electronically adjustable by made of moveable louvers. In tall 
buildings, when the cavity is over 20 meters, an area of low pressure can occur: this can block the chimney effect and consequently, the need to move this critical area as high as possible. One solution should be to design the outlet air vent (at the top), according to a generalized average of 2 to 1 respect to the inlet air vent (at the bottom).

\section{Conclusions}

Double skin glass façades are in the most cases used in the refurbishment of office and public buildings where high investment costs can be justified with the architectural renovation of the building. In the summer season in Italy, the maximum performance obtainable from a naturally ventilated double skin glass façade is mainly to act as a "buffer space" to reduce overheating. This implies that the main result that could be obtained is the reduction of operating costs for cooling, due to the increased thermal performance of the envelope.

All of these case studies demonstrated that a reduction of energy consumption both in summer that in winter season is possible: the average consumption of the buildings before the interventions was about $250-270 \mathrm{Kwh} / \mathrm{m}^{2}$, that was reduced of about $30-40 \%$ thanks to the realization of the new envelope. The most suitable solution might be an integrated plant that regularly provide for a mechanical ventilation of the cavity and it should be operative when the outside conditions are extreme. An interesting way that might really enhance the management of the energy balance, should also include to support the system with integrated photovoltaic panels or solar collectors, combining the benefits offered by the double skin structure (in terms of ventilation, noise protection and control of the pressure exerted by the wind), with the possibility of an active exploitation of the solar energy.

The payback for incremental investment in energy efficiency using a double glass envelope has been estimated at 20-25 years. Investment costs could have a fast payback if the glass envelope integrates active solar energy devices (e.g. photovoltaic systems).

\section{References}

[1] A Compagno, Intelligent glass facades, Birkhauser, Berlin, 1999.

[2] C. Schittich, Building Skins. Concepts, layers, materials, Birkhauser, Berlin, 1999

[3] S. Brunoro, Efficienza energetica delle facciate, Maggioli, Rimini, 2006

[4] Brunoro Silvia, Technical improvement of housing envelopes in Italy, in: Bragança L., Wetzel C., Buhagiar V., Verhoef L.G.W. (edited by), COST C16 Improving the quality of existing urban building envelopes. Facades and roofs, Volume 5, IOS Press, Amsterdam, 2007, pp.69-82

[5] S. Brunoro, An assessment of energetic efficiency improvement of existing building envelopes in Italy, in: Management of Environmental Quality. An international Journal, Volume 19, Number 6, 2008 